\title{
Design Requirements of Tools Supporting Reflection on Design Impact
}

\author{
Qiong Peng ${ }^{1}$ and Jean-Bernard Martens ${ }^{2}$ \\ 1,2 Eindhoven University of Technology, Eindhoven, the Netherlands \\ q.peng@tue.nl
}

\begin{abstract}
Designing for experience requires designers to pay attention to reflection on design impact. However, industrial design students are observed to have difficulty in demonstrating the impact of their design concepts due to insufficient thinking and reflection on design impact. There is a lack in the literature on both reflections on design impact and the tool support. The existing tools for general reflection purpose seem not to work well for this specific purpose. In response to the calls for designing for reflection, this paper presents two exploratory studies and the design requirements of tools for reflection on design impact. The purpose aims to facilitate design students for their reflection on design impact through developing appropriate tools. The design requirements could be generally used as guidelines or reference for future work of developing tools for reflection on design impact.
\end{abstract}

Keywords : Designing for reflection, Design impact, Tools, Design requirements

\section{$1 \quad$ Introduction}

Creative design is a process of co-evaluation of design problem and solution [1], involving a journey of self-exploration for designers [2]. It is defined as a reflective conversation with materials [3], reflection thus plays a vital role in such kind of process as a powerful tool of connecting thought [4] and promoting understanding of design space and problems [5]. Meanwhile, design is a situated and constructive making of meaning [6], it as an intervention influences people' thinking and action. The current designing for experience particularly fills designers with the responsibility to be aware of the impact of their design(concepts) on people and the world. Hence, designers actually design the impact, no the product [7, 8], and reflection on the design impact (or the impact of the design concept) allows industrial designers to think about the impact related aspects such as value, emotion, experience, feeling, and influence etc., instead of merely focusing on attributes of a product. However, industrial design students are prone to work around the product. Without thinking and reflection these impact aspects, design students are observed to have difficulty in demonstrating the design impact of their products when in communication with others. 
There has been a substantial amount of literature of reflection on design. Different aspects such as reflection techniques and methods [9, 10], tools, reflection-in-action [11], etc., have been discussed in previous work, but relatively little work focuses on reflection on design impact. Reflection is viewed hard [12] and critical reflection is never effortless. It is still challenging for students [13]. Appropriate methods, techniques or tools for reflection practice are potentially helpful. Within HCI, the growing interest in designing for reflection $[5,14,15,16]$ allows designers to design technology-supported tools to facilitate their own design reflection practice as well as the reflective practice that is conducted by both the public and other professional practitioners for different purposes. There have been many tools, especially technology-based one, for design reflection, and most of them are more focused on encouraging reflection by enhancing awareness of the situation, providing and documenting materials and structuring the reflection process [17]. Since fewer prior studies about reflection on design impact and tool support can be found as reference, we proposed a study based on three main research questions to explore insights into reflection on design impact.

Q1: What do the industrial design students usually reflect upon in their design practice? (to identify the lack of reflection on design impact)

Q2: How do the design students perform reflection on design impact? (to identify the needs for alternative tools as support)

Q3: What could the tools for reflection on design impact be? (to identify the design requirements for developing tools for reflection on design impact)

In this paper, we present two separate exploratory studies related to answering these questions. Key findings indicated the needs for alternative tools in support of reflection on design impact. And the insights extracted from the studies helped us to outline the design requirements for tools supporting for this specific purpose. We aim to fill in the gap in the empirical studies in the area of design reflection by focusing on discussing designing tools for reflection on design impact. It is in accordance with designing for experience, and also in response of the calls for designing for reflection. The proposed design requirements could be used as guidelines or reference when designing specific tools for reflection on design impact.

The paper is started with a literature review on both the theoretic and empirical work around reflection in context of creative design, and then two studies are explained and the results are reported. It concludes with the discussion of the design requirements of tools supporting reflection on design impact.

\section{$2 \quad$ Related work}

The growing interest in designing for reflection in $\mathrm{HCI}[5,14,15,18,19,20]$ triggers both research and design for supporting reflection in the fields such as education, medical care and design, etc. The concept of reflection is primarily defined as a cognitive process of inquiry $[21,22]$ and a mechanism of learning from experience [22]. As it is 
often criticized as a fuzzy concept [23-28], people practice reflection with the same term but with different definitions in different domains [15] for different purposes. In design pedagogy, reflection is viewed the activities that designers do with to understand the design space, generate alternative solutions and test them by repeatedly reframing the problem [11]. Reflection is regarded crucial to creative design with a large body of studies [29-32] which are primarily informed by Schon's articulation of reflective practice and his distinction of three types of reflection: reflection-in-action, reflection-onaction $[3,11]$. The benefits of design reflection are richly interpreted in literature such as making unconscious aspects of experience "available for conscious choices" [33], improving effectiveness and efficiency of design process [34], promoting design communication [35], facilitating design management [36] and supporting learning from design [10] etc. These benefits in turns confirm the increasing interest in designing for design reflection.

The focus of design nowadays has shifted from designing artefacts towards designing for experience [37], which allows designers to take the impact of design on people into account. It refers to the aspects such as user experience, emotions, values, etc. Friedman has early emphasized reflection on the value commitments embedded in a design through value-sensitive design [38]. Designing for experience, deeply based on usercentered design methodology, requires designers not to take their design concepts for granted without thinking about the impact on people. Reflection on the design impact is a deliberate process that can elicit thinking and analyzing the influence of the design on the targeted users and stakeholders, and even to the world. Hence, reflection on the design impact as well as the support for such kind of reflection should been given equal weight to when thinking about designing for reflection. Unfortunately, not many prior studies could be found.

When it comes to designing for reflection within design context, the principles and strategies of reflective design [39] are potentially helpful. Both the reflective informatics with three dimensions including breakdown, inquiry and transformation [16], and the five hierarchical levels of reflection [15] provide suggestions for designing for reflection. Slowness [40] which is in accordance with Reymens' suggestions of creating time [41] to encourage reflection could be intentionally designed to make space for reflection. However, as situated in design context, designing for design reflection is relatively more complex. This can be interpreted from two perspective. Design reflection broadly refers to the design process including both the design situation and the design activities [41], the design outputs like design concepts in the form of sketches, prototypes, etc., and other design materials generated during a design project, such as the reports, diaries, notes of communication, and audio or video records, ect. Whilst, there are different levels of design reflection which occurs at different phases as either reflection-in-action or reflection-on-action in the dynamic design process. Prior work has explored designing for design reflection by utilizing visualization. Examples are the Maps for reflection [42], Interactive Sketching [43] which increases the talk-back of design representation; Freed [44] which enables designers to create visual-spatial views of design work to support design reflection, the ReflectionSpace [45] and the 
ReflecTable [46], etc. An approach of using two-dimensional positioning of objects is also presented as a means of reflection [47] The support for revisiting and sharing by improved documentation or video is another design direction, examples are WorkSpace Nagivator [48], Designers' Outpost [49], Mindtap [50] and NOOT [51]. Besides, video is employed to support critical reflection in combination with story-making [30]. However, these tools are predominately designed either to encourage reflection by enhancing awareness of the situation, or to support reflection by improved documenting materials and structuring the reflection process. They are generally suitable when reflecting on the design process, design activities, design strategies, etc. Less focus was especially on reflection on design impact and the tool support. Hence, in designing for experience, we argue sufficient attention to the reflection on design impact (especially impact on people). And we particularly focus on designing (tools) for such kind of reflection. The lack of tool support calls for developing appropriate alternatives. We try to extent the exiting work by combining the fruitful results from literature review with our exploratory investigation.

\section{$3 \quad$ Methodology}

To meet the gap and facilitate design students for their reflection on design impact, we conducted two separate studies. We first made a set of interview sessions with 25 design students in our industrial design department to get a holistic understanding of their practice of design reflection. Each of the semi-structured interview session lasted for one hour and audio recorded, then later transcribed and analyzed. Participants included undergraduate students, master students and PhD students. They were first asked to interpret their own understanding of design reflection. This helped to ground the following questions focusing on the reflection on the design impact and the problems that they encountered. Participants were encouraged to provide explanation in more details. We also asked the participants to share their opinions on the tools that could better facilitate reflection on design impact in order to identify the needs for alternative better tools and collect insights and suggestions for tool design.

The results in the first study indicated that the design students' notions on design impact were not clear enough, and thus these vague notions influenced their practice of reflection on design impact. Meanwhile, it also implied a demand for alternative tools as the current tools didn't facilitate the specific reflection on design impact. Hence, in the second study, a co-design workshop with a task that to propose suggestions for developing tools in support of reflection on design impact was conducted with 12 design students. The reasons of co-workshop lay in the benefits of involving the design students in the design process, in which they contributed their personal experience and knowledge to generation of new ideas. Furthermore, they were more engaged and empathetic through designing for themselves. Reflection on design impact was explained to the participants when giving the task at the beginning of the workshop. The researchers worked together with the participants to co-develop the design ideas. The workshops were structured designed, and the participants worked in groups following the 
procedure: getting the design task --- task analysis --- brainstorming (for divergence) -- discussion the design ideas. The purpose of the workshop was to collect ideas about tool design, and a final design concept was not required. Instead, participants were encouraged to contribute ideas with more detailed information such as features, attributes, functionalities, interaction, etc. The whole process of each workshop lasted for 2 hours and then closed with an informal interview as supplement to collect information that was not delivered during the design procedures.

\section{$4 \quad$ Results}

\subsection{Results of study 1}

The interview sessions with 25 participants including 10 undergraduate students (42.9\%), 10 master students (42.9\%) and $5 \mathrm{PhD}$ students (14.2\%). The PhD students shared their opinions from the perspectives of being design practitioners rather than being design researchers. All of the participants reported that they had the experience in reflection upon the design practice either in the formal style like writing a report and making a presentation, or in the way that the believed as performing reflection such as sketching, discussion with team members, and self-thinking.

The answers to the questions (samples shown in table 1) in the interviews were transcribed verbatim and individual quotes were extracted and labelled. 2 researchers were involved in the quote coding process separately to guarantee the consistency of the coding process. 5 categories with 219 quotes in total were finally identified.

Category 1 included 52 quotes related to the definition of reflection. $73 \%$ of them defined reflection in design practice with relatively clear purposes, for instance, "Reflection is the deep-thinking of the design activities and process.", "Reflection means reviewing the design process and output to get new insights.", and "Reflection for me is the process in which I carefully think of the related aspects of my design work and then I can gain knowledge and experience." While the other $27 \%$ quotes contained vague definitions which simply equated to the terms like thinking, discussion and meditation, etc. These quotes indicated that all the participants gave their definitions of reflection as a process or an activity that occurs in the design practice, and the difference lies in the purpose of doing it, since no quotes mentioned a clear distinction between reflection-in-action and reflection-on-action.

Table 1. Sample of questions that were asked in the interviews.

\begin{tabular}{ll}
\hline No. & \multicolumn{1}{c}{ Questions } \\
\hline 1 & How do you define design reflection? (your definition) \\
2 & What do you usually reflect upon? (the content in your reflection) \\
3 & Did you make reflection particularly on the design impact or on the impact of \\
4 & your design (concept)? Why/why not? \\
& What are the problems that you encountered when you reflect on design impact?
\end{tabular}


5 Any methods or tools to support? Did they work well? Why/why not?

6 If any tool could help, what the tool could be? (suggestions for the tools)

Category 2: What to reflect upon (35 quotes): Each participant explained what they usually reflect upon. It covered nearly all the related aspects such as the design activities, design procedure, methods, tools, design strategies, design decision, design outcomes, etc. $28.5 \%$ quotes mentioned the terms like "influence", "affect", "impact" that were related to reflection on design impact.

Category 3: about reflection on design impact (65 quotes). 25 quotes were answers to experience in reflection on design impact, in which $20 \%$ quotes showed negative answers with the interpretations such as "I never think about the impact of the design. I usually make reflection when I have a problem and then think about how to solve it." "I must acknowledge that I might never or little think about the impact of my design. It seems that I actually neglected it." While, the remaining $80 \%$ quotes explained different consideration of reflection on design impact. For instance, "Yes, I think about the impact because I must envision the interaction between the user and my product." "User experience is important to think about. I think my reflection on design impact is related to the aspects of user experience." The other 40 quotes delivered problems that the students encountered when they reflect on the design impact. For instance, "I don't know how to reflect on design impact because I am not sure what the design impact means." "Design impact is too abstract to explain and reflect on. Guidelines or methods are necessary." "I don't know how to make reflection, and how to reflect on the design impact. I always perform reflection in my own way and I don't know whether it is right or not."

Category 4: Tools for support (30 quotes). $40 \%$ quotes showed no specific tools for reflection on design impact. The other $60 \%$ quotes mentioned the tools that were generally used for reflection (shown in figure 1). Both the traditional tools such as pen and notebooks, and the digital tools were applied. The diagram tools and mind map software were also introduced by the participants as tools for reflection for design impact.

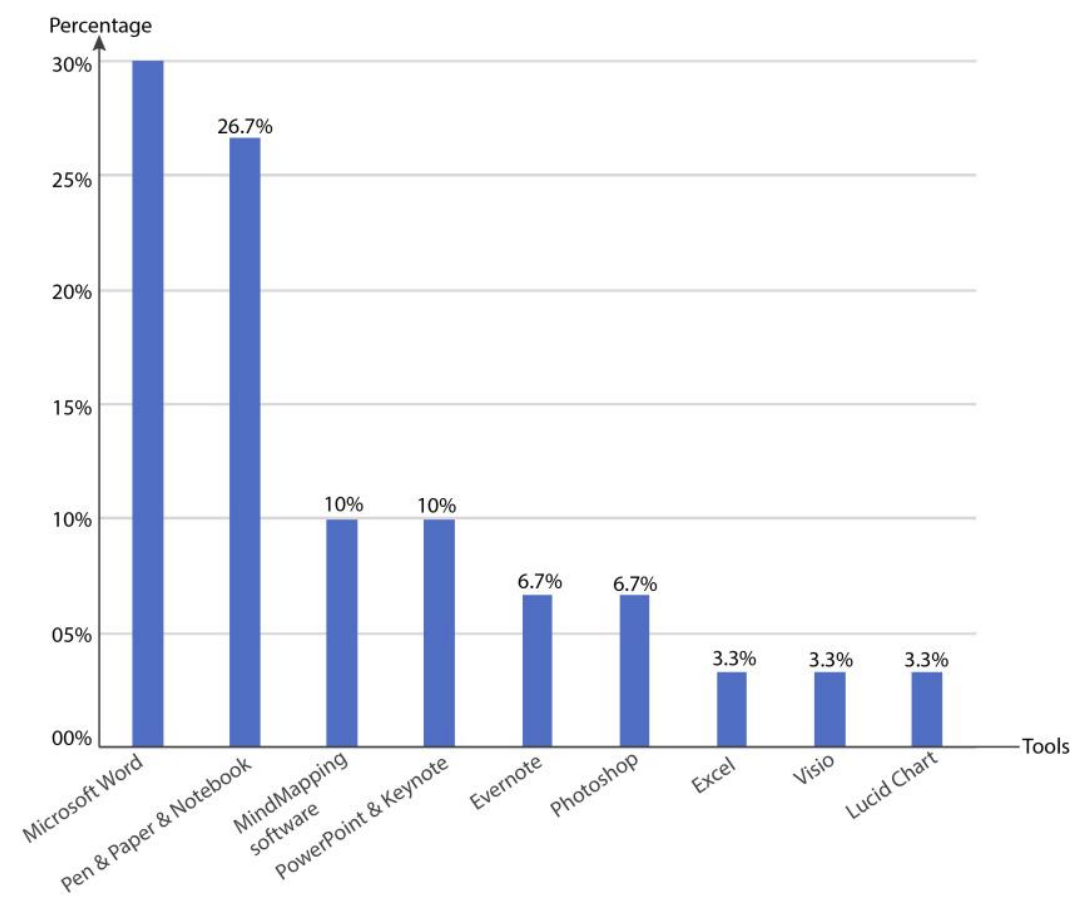


Fig. 1. Tools that were mentioned in the quotes by the students. Microsoft Word for $30 \%$, the traditional tools like pen and paper, notebook for $26.7 \%$, Mind mapping software for $10 \%$, PowerPoint and Keynote for $10 \%$, Evernote for $6.7 \%$, Photoshop for $6.7 \%$, Excel for 3.3\%, Visio for 3.3\%, Lucid Chart 3.3\%.

Category 5: needs for alternative tools (37 quotes). Participants placed emphases on the needs for appropriate tool to support reflection on design impact. For instance, "Because I mostly make reflection in my own way which is time-consuming, I believe that it could be improved by some good tools." "I actually don't know how to reflect on the design impact, so methods or tools are necessary." "I believe that tools are in need. Design impact is too abstract to think about and I even don't know how to start the reflection." In addition, nearly half of the quotes in this category showed complaint or dissatisfaction with the existing tools, as the quotes explained "I didn't use any specific tools for reflection on design impact as these tools seem not appropriate." "Tools like Mindmap can be used for reflection on impact, as it helps to connect the aspects. The other tools might not facilitate."

\subsection{Results of study 2}

In these workshops, 12 participants including the 50\% undergraduate students and $50 \%$ master students participated in the co-design workshop. A task was given to the participants by introducing the items and requirements (shown in table 2) to ensure our research purpose. More than 15 ideas based on the given design task were proposed and discussed.

Table 2. Items of the task introduction.

\begin{tabular}{ll}
\hline Items & Requirement \\
\hline Design for whom & design students \\
Using context & Designing tools for reflection on design impact \\
& Need to identify the design problems when reflect- \\
To solve what problems & ing on design impact \\
What the design solutions(tools) could & Related technology to support \\
be? & Functionalities, interaction design... \\
How it works? & Identify how your design ideas support reflection \\
About design Impact & on a design impact and how people use it \\
\hline
\end{tabular}




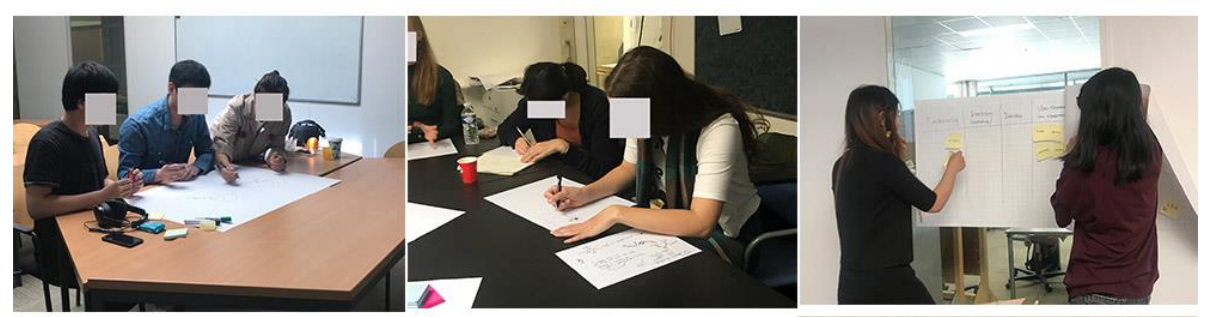

Fig. 2. Photos of the workshop.

These ideas which were proposed for different specific problems were categorized into three main types. Some ideas were generated with emphasis on clear guidelines and procedures as the participants explained "only given specific support, the reflection on design impact could be easy to do." Some ones were about tools which provide the introduction and examples of design impact as explained that "If we don't know what design impact it is, we neither pay attention to it nor make good reflection on it." The ideas focusing on the support of visualizing and analyzing the design impact were also proposed.

In the interview, participants added more information about explanation of the problem as well as their expectations on the solutions. The data was collected and transcribed verbatim into quotes, and then analyzed by sorting into 2 categories: $\mathrm{C} 1$ : definition of the problems (27 quotes, shown in table 3); C2: What the tool could be (59 quotes, shown in table 4$)$.

Table 3. Sub-categories of category 1 and example.

\begin{tabular}{|c|c|c|}
\hline Sub-category & $\begin{array}{l}\text { Quote } \\
\text { No. }\end{array}$ & Example \\
\hline $\begin{array}{l}\text { [1] Lacking practical methods } \\
\text { or guidelines }\end{array}$ & 8 & $\begin{array}{l}\text { "Any specific procedures to support re- } \\
\text { flection on the design concept?" }\end{array}$ \\
\hline $\begin{array}{l}\text { [2] Lacking clear interpreta- } \\
\text { tion of design impact }\end{array}$ & 6 & $\begin{array}{l}\text { "What is design impact? If I don't know } \\
\text { what it is, how can I reflect on it?" }\end{array}$ \\
\hline $\begin{array}{l}\text { [3] No feedback on the re- } \\
\text { sults of reflection }\end{array}$ & 4 & $\begin{array}{l}\text { "If the impact means values to the users, } \\
\text { how can I get to know whether they get it } \\
\text { or not after my reflection?" }\end{array}$ \\
\hline $\begin{array}{l}\text { [4] Design impact is abstract } \\
\text { to reflect upon }\end{array}$ & 9 & $\begin{array}{l}\text { "Design impact seems abstract. I don't } \\
\text { know how to effectively think about } \\
\text { them." }\end{array}$ \\
\hline
\end{tabular}


Table 4. Sub-categories of category 1 and example.

\begin{tabular}{lll}
\hline \multicolumn{1}{c}{$\begin{array}{c}\text { Sub- } \\
\text { category }\end{array}$} & $\begin{array}{l}\text { Quote } \\
\text { NO. }\end{array}$ & \multicolumn{1}{c}{ Example } \\
\hline $\begin{array}{l}\text { [1] supporting interpretation } \\
\text { of design impact }\end{array}$ & 13 & $\begin{array}{l}\text { "The tool should provide tips or remind- } \\
\text { ers to help designers to understand design } \\
\text { impact." }\end{array}$ \\
$\begin{array}{l}\text { [2] supporting visualization } \\
\begin{array}{l}\text { and analysis of the aspects re- } \\
\text { lated to describe design im- } \\
\text { pact }\end{array}\end{array}$ & 21 & $\begin{array}{l}\text { "If there are some elements or factors to } \\
\text { explain design impact, the tool should vis- } \\
\text { ualize them and support the analysis." }\end{array}$ \\
$\begin{array}{l}\text { [3] supporting a structured } \\
\text { way to review and connect } \\
\text { design elements }\end{array}$ & 25 & $\begin{array}{l}\text { "Maybe a framework or structure to con- } \\
\text { nect the design concept, its impact and us- } \\
\text { ers, context together could help." }\end{array}$ \\
\hline
\end{tabular}

\section{Discussion}

\subsection{Understanding reflection on design impact}

Designing for reflection should firmly be based on deep understanding of reflection itself, including the definition, content, purpose, method, tools and results, etc. The less known details of student designers' reflection practices not only paints reflection as an unstructured and inefficient process, but also results in limited support by tools for facilitation. Some insights are worth discussing as follows.

\section{Lack sufficient attention to reflection on design impact}

The design students in our studies had relatively vague definition of design reflection because most of them interpreted their definition of design reflection with many different terms such as meditation, mindfulness, awareness, stillness, and deep-thinking, review, as well as discussion, self-assessment, etc. Students tended to associate the purposes or goals to reflection, and they mostly performed reflection triggered by a specific design need. Many aspects such as the design process, activities, methods, outputs, knowledge, as well as design problems, solutions etc. thus become the content to reflect on. Meanwhile, students seemed to be not clear about the notion of design impact. They articulated design impact based on their own understanding such as influence, benefits, values, and meanings, etc. Consequently, when reflecting on the design concepts, the reflection particularly focusing on design impact was relatively weak or easily neglected, as some participants in the first study clearly expressed that they never reflect on the design impact. The others who believed that they actually made reflection on design impact, but without more explanation of what the design impact is and how they did it. Design impact is primarily related to value [7] that a (product) design brings to people and the world. Based on user-centered design methodology and designing for experience, the meaning of design impact could be extended from value to the user- 
related aspects including emotion, experience, feeling, and the change in action, etc. $[52,53]$ Without understanding of design impact, it is impossible for designer (students) to practice reflection on it.

Guidelines for design reflection on design impact are beneficial.

The student designers complained that they had difficulties in reflection primarily due to the lack of specific methods or guidelines. The unstructured process and chaotic procedure greatly affect effectiveness and efficiency of their reflection performance. Blaiklock highlights the benefits of structure in design that reaching a high level of academic literacy, critical reflection and knowledge construction [54]. Daudeline proposes structured approach to reflection as "coached" reflection which involves providing formal tools to help thinking through an experience in order to identify what they learned from [55]. Reymen's recommendation that to perform design reflection on action at the beginning or end of a design session guided in a structured procedure with three main activities consisting preparation, image forming, and conclusion [41] could be used as the methodology for reflection performance. The preparation refers to the materials that are the basis for reflection on action, as Schon stresses that design is a reflective conversation with the materials.

\section{A demand for tools support reflection on design impact}

The insights collected from our studies indicated the needs for appropriate tools in support of reflection on design impact. Design students predominately made reflection in their own ways with various tools including the traditional tools such as notebook, pen, post-it, and some digital tools such as Microsoft Word, PowerPoint, Evernote, Photoshop, ect. As to reflection on design impact, these tools potentially support, but seems not match well. This is one of important the reasons that participants in our studies called for alternative tools as support. Reflection is a cognitive activity which takes time and effort. Appropriate tools for support can enhance the efficiency, engagement of reflection performance, and improve the experience during the reflection process and the outputs.

\subsection{Design requirement of tools supporting reflection on design impact}

Tools for reflection are not absolutely essential, but appropriate tools can assist the reflection performance. What the tools for reflection on design impact would be? Based on the literature review and the results of our two studies, especially the insights from the workshops, we anchored the attention to the design requirements for such kind of tools rather than focusing on single tool design. Developing an appropriate tool is always challenging. These design requirements can be used as reference when thinking about designing tools for reflection on design impact. When it comes to design for reflection, design directions like design for pauses, design for detachments, design for serendipity are worthwhile pursuing. Dalsgaard et al discuss some features like comparation and expansion for further development of their reflection maps [42]. Based on all of these prior research work, we summarize the design requirements of tools for reflection on design impact encompassing the following 3 aspects: 
Firstly, with a unique style to differentiate from other tools.

Tools should be designed with clear features for supporting reflection design impact. Providing interpretation of design impact to the users is necessary, so that designers (students) can distinguish with the other tools that are for general reflection purposes. Explicit definition on functionality could work as scaffolding to avoid a random use of tools by the design students. Many existing tools that students utilize are not particularly developed for reflection, whilst some tools for reflection generally support design reflection like supporting documentation and visualization. It makes the tool users perplexed when deciding which tool is more appropriate for a specific purpose. The tool design thus is need-specific.

Secondly, narratives or storytelling could be used to provide a framework that involves in all the related elements to support discussion and reflection on design impact. Narratives or storytelling is regarded powerful for reflection and reflective practice [5658]. Design impact is abstract and not easy to be interpreted. Reflection on design impact is challenging. Narratives or storytelling makes it accessible to thinking about impact by organizing the underlying aspects such as people, context and people's emotions, values into a structure. Hence, tools for reflection on design impact could be architecture with a narrative or storytelling framework. They can support designers to have discussion, envision and analysis on these aspects based on the narrative or storytelling framework. The narrative or storytelling itself is the material that designers (students) could have a conservation with.

Finally, designing tools for reflection on design impact should allow collaborative support either in the way of co-reflection or by involving in external feedback. The impact of a design is actually perceived by users or stakeholder, and designers design and reflect on the impact primarily based on their own judgement or imagination. Design reflection is different from design rationale or design critiques. It is large conceptualized as individual mental activity [59], but also has strong social dimensions [25]. Without external feedback, the reflection on design impact is performed in a blank box. The co-reflection, or collaborative reflection is a collaborative critical thinking process [60] which combines individual cognition and interaction between individuals. The sharing understanding through collaborative reflection can promote designers to critically rethink about the impact that their design would bring to people and even to the world. Technologies own unique advantages in supporting collaboration and feedback communication. Taking advantage of technology support is an important consideration when designing tools for reflection on design impact.

\subsection{Limitations and future work}

The huge body of research on reflection as well as design for reflection provides both opportunities and challenges for design research. In our research, we placed the background of designing for experience in which the design impact is highlighted, and the background of designing for reflection in which technology is extensively utilized to 
support reflection practice. We aim to better to facilitate students' reflection on design impact through developing tools. The results were based on exploratory studies which were primarily conducted by qualitative research methods like interviews and workshops. The design requirements are still theoretical proposition which could only be used as reference. There is space for modification and improvement. We believe that in-deep observation and long-time-tracking of their reflection practice in different design projects could bring us more insights.

Besides the purpose of learning by engagement of design reflection, designers can also benefit to get better sense of their design work [61] for other purposes like communication. Narratives and story constructions which are effective means of reflection are also highly recommended for the sense-making for the design work. Both the literature and propositions of developing storytelling tools for design reflection from the workshops informed us a specific direction for our future work.

\section{Conclusion}

In this paper, we presented two studies about exploring design tools for reflection on design impact. We particularly focused on reflection on design impact in order to enhance the awareness of design impact in the context of designing for experience. And proposed the design requirements for tools in support of reflection on design impact. Reflection is a crucial part of the creative design, and we believe that appropriate tools can facilitate design students' reflection practice and promote the awareness of performing reflection frequently with the support of the excellent tools. The proposed design requirements could be regarded as a starting point for future work and invite interested researcher to join in this work.

\section{Acknowledgements}

This research is part of the $\mathrm{PhD}$ research. It was also supported by the funding WLWH17-23 and 2016ZO36. Appreciations for all the participants for interviews and workshops.

\section{References}

1. K. Dorst and N. Cross, "Creativity in the design process: co-evolution of problem-solution," Design studies, vol. 22, no. 5, pp. 425-437, 2001.

2. S. G. English, "Enhancing the Reflective Capabilities of Professional Design Practitioners," 2009.

3. D. A. Schon, "Designing as reflective conversation with the materials of a design situation," Research in Engineering Design, vol. 3, no. 3, pp. 131-147, Sep. 1992.

4. R. Luppicini, "Reflective Action Instructional Design (RAID): A Designer's Aid," International Journal of Technology and Design Education, vol. 13, no. 1, pp. 75-82, Jan. 2003 
5. E. P. Baumer, V. Khovanskaya, M. Matthews, L. Reynolds, V. Schwanda Sosik, and G. Gay, "Reviewing reflection: on the use of reflection in interactive system design," in Proceedings of the 2014 conference on Designing interactive systems, 2014, pp.93-102.

6. S. Ylirisku, V. Halttunen, J. Nuojua, and A. Juustila, "Framing Design in the Third Paradigm," in Proceedings of the SIGCHI Conference on Human Factors in Computing Systems, New York, NY, USA, 2009, pp. 1131-1140.

7. T. Brown and B. Katz, "Change by design," Journal of product innovation management, vol. 28, no. 3, pp. 381-383, 2011.

8. M. Camacho, "David Kelley: From design to design thinking at Stanford and IDEO," She Ji: The Journal of Design, Economics, and Innovation, vol. 2, no. 1, p. 88, 2016.

9. "Improving design processes through structrued reflection." .

10. I. M. M. J. Reymen, "RESEARCH ON DESIGN REFLECTION: OVERVIEW AND DIRECTIONS," in DS 31: Proceedings of ICED 03, the 14th International Conference on Engineering Design, Stockholm, 2003.

11. D. A. Schon and V. DeSanctis, The reflective practitioner: How professionals think in action. Taylor \& Francis, 1986.

12. J. Prior, S. Ferguson, and J. Leaney, "Reflection is Hard: Teaching and Learning Reflective Practice in a Software Studio," in Proceedings of the Australasian Computer Science Week Multiconference, New York, NY, USA, 2016, pp. 7:1-7:8.

13. K. Kori, M. Pedaste, Ä. Leijen, and M. Mäeots, "Supporting reflection in technology-enhanced learning," Educational Research Review, vol. 11, pp. 45-55, Jan. 2014.

14. C. Sas and A. Dix, "Designing for Reflection on Experience," in CHI '09 Extended Abstracts on Human Factors in Computing Systems, New York, NY, USA, 2009, pp. 4741-4744.

15. R. Fleck and G. Fitzpatrick, "Reflecting on reflection: framing a design landscape," in Proceedings of the 22nd Conference of the Computer-Human Interaction Special Interest Group of Australia on Computer-Human Interaction, 2010, pp. 216-223.

16. E. P. S. Baumer, "Reflective Informatics: Conceptual Dimensions for Designing Technologies of Reflection," in Proceedings of the 33rd Annual ACM Conference on Human Factors in Computing Systems, New York, NY, USA, 2015, pp. 585-594.

17. R. Fleck, "Designing for Reflection, Sustainability and Simplicity," p. 4.

18. I. Li, A. Dey, and J. Forlizzi, "A stage-based model of personal informatics systems," in Proceedings of the SIGCHI conference on human factors in computing systems, 2010, pp. 557-566.

19. E. P. S. Baumer, "Reflective Informatics: Conceptual Dimensions for Designing Technologies of Reflection," in Proceedings of the 33rd Annual ACM Conference on Human Factors in Computing Systems, New York, NY, USA, 2015, pp. 585-594.

20. P. Slovák, C. Frauenberger, and G. Fitzpatrick, "Reflective Practicum: A Framework of Sensitising Concepts to Design for Transformative Reflection," in Proceedings of the 2017 CHI Conference on Human Factors in Computing Systems, New York, NY, USA, 2017, pp. 2696-2707.

21. J. Dewey, How we think. Courier Corporation, 1997.

22. J. A. Moon, Reflection in learning and professional development: Theory and practice. Routledge, 2013.

23. N. Hatton and D. Smith, "Reflection in teacher education: Towards definition and implementation," Teaching and teacher education, vol. 11, no. 1, pp. 33-49, 1995.

24. E. A. Davis, "Characterizing productive reflection among preservice elementary teachers: Seeing what matters," Teaching and teacher education, vol. 22, no. 3, pp. 281-301, 2006.

25. H. Procee, "Reflection in education: A Kantian epistemology," Educational theory, vol. 56, no. 3, pp. 237-253, 2006. 
26. S. Quinton and T. Smallbone, "Feeding forward: using feedback to promote student reflection and learning-a teaching model," Innovations in Education and Teaching International, vol. 47, no. 1, pp. 125-135, 2010.

27. M. Clarà, "What is reflection? Looking for clarity in an ambiguous notion," Journal of Teacher Education, vol. 66, no. 3, pp. 261-271, 2015.

28. B. Renner, M. Prilla, U. Cress, and J. Kimmerle, "Effects of prompting in reflective learning tools: Findings from experimental field, lab, and online studies," Frontiers in psychology, vol. 7, p. 820, 2016.

29. P. Sengers, K. Boehner, S. David, and J. "Jofish" Kaye, "Reflective design," presented at the Proceedings of the 4th decennial conference on Critical computing: between sense and sensibility, 2005, pp. 49-58.

30. J. McDonnell, P. Lloyd, and R. C. Valkenburg, "Developing design expertise through the construction of video stories," Design Studies, vol. 25, no. 5, pp. 509-525, Sep. 2004

31. K. Lauche, "Heedful action, reflection, and transfer in the design process," WDK Publications, pp. 267-274, 2001.

32. P. Badke-Schaub, S. Wallmeier, and D. Dörner, "Training for designers: a way to reflect design processes and cope with critical situations in order to increase efficiency," in International Conference on Engineering Design, August, 1999, pp. 24-26.

33. P. Sengers, K. Boehner, S. David, and J. "Jofish" Kaye, "Reflective Design," in Proceedings of the 4th Decennial Conference on Critical Computing: Between Sense and Sensibility, New York, NY, USA, 2005, pp. 49-58.

34. I. M. M. J. Reymen, "RESEARCH ON DESIGN REFLECTION: OVERVIEW AND DIRECTIONS," DS 31: Proceedings of ICED 03, the 14th International Conference on Engineering Design, Stockholm, 2003.

35. R. Valkenburg and K. Dorst, "The reflective practice of design teams," Design studies, vol. 19, no. 3, pp. 249-271, 1998.

36. K. Lauche, "Facilitating Creativity and Shared Understanding in Design Teams," DS 30: Proceedings of DESIGN 2002, the 7th International Design Conference, Dubrovnik, 2002.

37. B. Atasoy and J.-B. Martens, "STORYPLY: designing for user experiences using storycraft," in Collaboration in Creative Design, Springer, 2016, pp. 181-210.

38. Friedman, B, "Value-sensitive design and information systems," interactions, vol. 3, no. 6, pp. 16-23, 1996.

39. P. Sengers, K. Boehner, S. David, and J. Kaye, "Reflective design," in Proceedings of the 4th decennial conference on Critical computing: between sense and sensibility, 2005, pp. 49-58.

40. C. F. Strauss and A. Fuad-Luke, "The Slow Design Principles," p. 14.

41. I. Reymen, Improving design processes through structured reflection: A domain-independent approach. Technische Universiteit Eindhoven, 2001.

42. P. Dalsgaard, K. Halskov, and R. Nielsen, "Maps for design reflection," Artifact, vol. 2, no. 3-4, pp. 176-189, 2008.

43. J. Lin, M. W. Newman, J. I. Hong, and J. A. Landay, "DENIM: finding a tighter fit between tools and practice for Web site design," in Proceedings of the SIGCHI conference on Human Factors in Computing Systems, 2000, pp. 510-517.

44. P. Mendels, J. Frens, and K. Overbeeke, "Freed: A System for Creating Multiple Views of a Digital Collection During the Design Process," in Proceedings of the SIGCHI Conference on Human Factors in Computing Systems, New York, NY, USA, 2011, pp. 1481-1490.

45. M. Sharmin and B. P. Bailey, "ReflectionSpace: an interactive visualization tool for supporting reflection- on -action in design," in Proceedings of the 9th ACM Conference on Creativity \& Cognition - C\&C '13, Sydney, Australia, 2013, p. 83. 
46. J. Hook, T. Hjermitslev, O. S. Iversen, and P. Olivier, "The ReflecTable: bridging the gap between theory and practice in design education," in IFIP Conference on Human-Computer Interaction, 2013, pp. 624-641.

47. K. Nakakoji, Y. Yamamoto, S. Takada, and B. N. Reeves, "Two-dimensional spatial positioning as a means for reflection in design," in Proceedings of the 3rd conference on Designing interactive systems: processes, practices, methods, and techniques, 2000, pp. 145154.

48. W. Ju, A. Ionescu, L. Neeley, and T. Winograd, "Where the wild things work: capturing shared physical design workspaces," in Proceedings of the 2004 ACM conference on Computer supported cooperative work, 2004, pp. 533-541.

49. S. R. Klemmer, M. Thomsen, E. Phelps-Goodman, R. Lee, and J. A. Landay, "Where do web sites come from?: capturing and interacting with design history," in Proceedings of the SIGCHI conference on Human factors in computing systems, 2002, pp. 1-8.

50. J. Nielsen and N. Christiansen, "Mindtape: a tool for reflection in participatory design," in PDC, 2000, pp. 309-313.

51. J. van Dijk, J. van der Roest, R. van der Lugt, and K. C. Overbeeke, "NOOT: a tool for sharing moments of reflection during creative meetings," in Proceedings of the 8th ACM conference on Creativity and cognition, 2011, pp. 157-164.

52. J. J. Garrett, Elements of user experience, the: user-centered design for the web and beyond. Pearson Education, 2010.

53. M. Hassenzahl, "User experience and experience design," The encyclopedia of human-computer interaction, vol. 2, 2013.

54. K. Blaiklock, "Te Whāriki, the New Zealand early childhood curriculum: is it effective?," International Journal of Early Years Education, vol. 18, no. 3, pp. 201-212, Sep. 2010.

55. K. W. Seibert, "Reflection-in-action: Tools for cultivating on-the-job learning conditions," Organizational Dynamics, vol. 27, no. 3, pp. 54-65, 1999.

56. S. A. Cake, L. Solomon, G. McLay, K. O'Sullivan, and C. R. Schumacher, "Narrative as a tool for critical reflective practice in the creative industries," Reflective Practice, vol. 16, no. 4, pp. 472-486, Jul. 2015.

57. C. Johns, Engaging reflection in practice: A narrative approach. Wiley-Blackwell, 2006.

58. G. Bolton, Reflective practice: Writing and professional development. Sage publiccations, 2010.

59. M. W. Daudelin, "Learning from experience through reflection," Organizational dynamics, vol. 24, no. 3, pp. 36-48, 1996.

60. J. Yukawa, "Co-reflection in online learning: Collaborative critical thinking as narrative," International Journal of Computer-Supported Collaborative Learning, vol. 1, no. 2, pp. 203-228, 2006.

61. M. Sharmin and B. P. Bailey, "I Reflect to Improve My Design": Investigating the Role and Process of Reflection in Creative Design," in Proceedings of the 8th ACConference on Creativity and Cognition, New York, NY, USA, 2011, pp. 389-390. 